\title{
The efficacy and safety of immune checkpoint inhibitor combination therapy in lung cancer: a systematic review and meta-analysis
}

This article was published in the following Dove Press journal:

OncoTargets and Therapy

Min Peng'

Xing $\mathrm{Li}^{2}$

$\mathrm{Gu} \mathrm{Lei}{ }^{3}$

Yi Ming Weng'

Meng Xue $\mathrm{Hu}^{\prime}$

Qi Bin Song'

'Department of Oncology, Renmin Hospital of Wuhan University, Wuhan University, Wuhan 430060, Hubei Province, China; ${ }^{2}$ Department of Urology, Renmin Hospital of Wuhan University, Wuhan University, Wuhan 430060, Hubei Province, China; ${ }^{3}$ Department of Pathology, Huangshi Central Hospital of Edong Healthcare Group, Huangshi 435000, Hubei Province, China
Correspondence: Qi Bin Song Department of Oncology, Renmin Hospital of Wuhan University, Wuhan University, Jiefang Road No 238, Wuhan 430060, Hubei Province, China

Tel/fax +86278804 I9l I

Email qibinsong@163.com
Abstract: The value of immune checkpoint inhibitor (ICI) combination therapy for patients with lung cancer remains unclear. We conducted a meta-analysis using PubMed, Embase, and ClinicalTrials.gov databases to identify eligible randomized controlled trials (RCTs) that might provide a reference for clinical practice. The selection criteria were defined according to the population, intervention, comparison, outcome and study design (PICOS) framework. In all, 12 RCTs with 5,989 patients were included in this meta-analysis. Our results showed that ICI combination therapy was significantly associated with the improvement of overall response rate (ORR) $(\mathrm{RR}=1.44$ [95\% CI 1.19, 1.74], $P=0.0002)$, progression-free survival (PFS) $(\mathrm{HR}=0.67$ [95\% CI 0.59, 0.77], $P<0.00001$ ), and OS (HR $=0.81$ [95\% CI 0.70, 0.95], $P=0.008$ ) in lung cancer. In subgroup analyses, combination ICI therapy significantly prolonged OS in nonsmall-cell lung cancer (NSCLC) patients ( $\mathrm{HR}=0.80$ [95\% CI 0.73, 0.88], $P<0.00001$ ) but not in SCLC $(\mathrm{HR}=0.94$ [95\% CI 0.82, 1.08], $P=0.40)$ patients. Data suggested that PD-1 inhibitors had higher efficacy and safety profiles than PD-L1 and CTLA-4 inhibitors in combination ICI therapy for lung cancer patients. Furthermore, tolerability analysis revealed higher incidences of grade $\geq 3$ AEs, fatigue, and increased transaminases from combination ICI therapy. In conclusion, our meta-analysis indicated that combination ICI therapy should be considered in clinical practice and future study designs for NSCLC patients. However, the current data do not support the large-scale clinical application of combination ICI therapy in SCLC patients.

Keywords: immune checkpoint inhibitor, lung cancer, combination therapy, chemoradiotherapy, meta-analysis

\section{Introduction}

Lung cancer accounts for the highest number of cancer-related deaths worldwide. ${ }^{1,2}$ Surgery, radiotherapy, and chemotherapy have improved survival for patients with localized lung cancer. However, treatment challenges remain for patients with advanced or refractory lung cancer. ${ }^{2,3}$ In the past few decades, the key role of the immune system in the development and progression of cancer has led to significant advancements in immunotherapy. Solid tumors have mechanisms for inhibiting the antitumor immune response, which include the release of inhibitory cytokines, the recruitment of immunosuppressive immune cells, and the upregulation of co-inhibitory receptors or immune checkpoints. These suppressive mechanisms contribute to cancer progression and immunotherapy failure as well. In the last 10 years, research has focused on the use of immune checkpoint inhibitors (ICIs) as an important introduction for cancer treatment. ${ }^{3-7}$ Currently, target checkpoints inhibited by monoclonal antibodies are cytotoxic T-lymphocyte-associated antigen-4 (CTLA-4), anti-programmed 
cell death-1 (PD-1) receptor, and its main ligand (CD274 or PD-L1). CTLA-4 and PD-1/PD-L1 inhibitors have been approved by the US Food and Drug Administration (FDA) for the treatment of non-small-cell lung cancer (NSCLC). ${ }^{3,8,9}$ Nevertheless, there is a need to improve treatment outcomes and combination therapy may be a promising strategy in this endeavor for lung cancer. ${ }^{10-12}$

The hallmark mechanisms of cancer immunotherapy include immunogenic cell death, antigen release, and presentation, priming of $\mathrm{T}$-cell responses, enhancement of T-cell activity, infiltration into tumor tissues, and depletion of compensatory immunosuppression. ${ }^{13}$ Preclinical studies show that the blockade of single negative costimulatory pathways often leads to enhanced effector T-cell (Teff) infiltration of tumors, but these $\mathrm{T}$ cells accumulate high levels of unblocked negative co-receptors that eventually limit their expansion. Combination blockade of the CTLA-4 and PD-1/PD-L1 pathways cooperates to increase the ratio of Teffs to regulatory T cells (Tregs) and MDSCs, thereby reducing immunosuppression and promoting inflammation in the tumor microenvironment (TME). ${ }^{14}$ Recent research has focused on improving the efficacy of currently available ICIs, and combining anti-CTLA-4 and anti-PD-1/PD-L1 inhibitors might be one such improvement strategy. ${ }^{8,10}$ The therapeutic potential of combinatorial approaches is highlighted by the recent US FDA approval of nivolumab plus ipilimumab for patients with advanced melanoma. ${ }^{14}$ Preclinical studies suggest that CTLA-4 and PD-1/PD-L1 pathway blockade has synergistic anticancer effects in various cancer cell lines. ${ }^{5,15-18}$ In early clinical trials, combination strategies offered anticancer effects with durable responses and manageable safety profiles for lung cancer. ${ }^{19-21}$ To confirm and extend those results, large clinical trials have been undertaken to examine the safety and efficacy of dual ICIs.

Chemotherapy leads to tumor cell death and release of antigens to initiate the activation of $\mathrm{T}$ cells, which may then migrate into tumor tissues. ${ }^{13}$ This anticancer immune response may help eliminate residual cancer cells that are survived in chemotherapy. In addition, preclinical researches have demonstrated that conventional cancer therapies (chemotherapy and radiotherapy) modulate the immune response against tumors and can induce the expression of PD-L1 in tumor cells. ${ }^{22-24}$ Based on these observations, several early clinical trials were designed to assess the combination of chemotherapy and ICI for patients with lung cancer. ${ }^{13,25}$ Early clinical data for the combination therapy of ICI and chemotherapy suggest that these regimens have manageable toxicity and promising antitumor activity for lung cancer. In the international, multicohort, Phase I/II KEYNOTE-021 study (ClinicalTrials.gov number NCT02039674), 17 of the 24 patients achieved an overall response and a median progression-free survival (PFS) of 10.2 months with pembrolizumab, carboplatin, and pemetrexed combination therapy. On May 10, 2017, the US FDA granted accelerated approval for pembrolizumab in combination with pemetrexed and carboplatin for the treatment of patients with previously untreated metastatic nonsquamous NSCLC. Similar to pembrolizumab, nivolumab was combined with platinum-based chemotherapy in the Phase I CheckMate 012 trial. The results suggested that nivolumab might improve outcomes and extend the survival of patients with advanced NSCLC in the first-line setting in combination with chemotherapy. ${ }^{13}$ However, the favorable results from Phase I and II trials that were the basis of the Phase III clinical trials often produced inconsistent results. ${ }^{26-28}$ Moreover, because these drugs modulate the immune response, immune-related adverse events (AEs) were reported. The fact that the efficacy of these drugs is synergistic suggests that their toxicity might be multiplied as well. ${ }^{29}$ Up to now, only one meta-analysis with a small number of patients has been reported, which focused on the combination immunotherapy in lung cancer. Due to a limited number of studies and the lack of long-term outcomes, further study of updated information is required. ${ }^{30-36}$ Following the completion of several large Phase III clinical trials (KEYNOTE407, IMpower131, Checkmate227, and IMpower150), the role of combination ICI therapy in lung cancer should be clarified. ${ }^{32,34,37-39}$ Therefore, our meta-analysis aims to provide more reliable and up-to-date evidence on the efficacy and safety of combination ICI therapy for lung cancer.

Therefore, the purpose of this meta-analysis was to address the following PICOS question: in patients with lung cancer (population), is there any difference of efficacy and safety (outcome) between combination ICI therapy (intervention), traditional therapy, or monotherapy (comparison)?

\section{Methods}

We conducted this meta-analysis on the basis of the PRISMA statement. All analyses were conducted based on previously published studies; thus, no ethical approval and patient consent are required.

\section{Search strategy}

Two reviewers (Yi Ming Weng and Min Peng) independently completed a search. The search strategy combined the following key words: ("Durvalumab" [All Fields]) OR ("Atezolizumab" [All Fields]) OR ("Nivolumab" [All Fields]) OR ("Pembrolizumab" [All Fields]) OR ("Tremelimumab" [All Fields]) OR ("Ipilimumab" [All Fields]) 
OR ("Immune checkpoint" [All Fields]) OR ("Immune checkpoint inhibitor" [All Fields]). We used this search strategy to search PubMed (https://www.ncbi.nlm.nih.gov/ pubmed), Embase (https://www.embase.com/login), and ClinicalTrials.gov (https://ClinicalTrials.gov/) website from inception to July 22, 2018. The American Society of Clinical Oncology (ASCO) and the European Society for Medical Oncology (ESMO) conference proceedings were searched from 2013 to 2018 . The search was limited to randomized clinical trials involving human published in English. No other limitation was used (ie, time period and peer review publication only). References of included studies and related reviews were checked manually. If the results of randomized controlled trials (RCTs) were published in a series of articles, only the most recent, complete report of the clinical trial was included for analysis.

\section{Inclusion criteria (population, intervention, comparison, outcome and study design [PICOS])}

All relevant articles underwent evaluation for eligibility by two investigators (Min Peng and Xing Li) independently. The selection criteria were defined according to the PICOS framework. This meta-analysis includes as follows: 1) population: participants with histologically confirmed lung cancer; 2) intervention: dual ICIs or ICI plus chemotherapy; 3) comparison: ICI alone or chemotherapy; 4) outcomes: endpoints included at least one of the following: ORR, PFS, OS, and AEs (adverse effects) of grade $\geq 3$; and 5) study design: RCTs.

\section{Data extraction and quality assessment}

Literature screening and data extraction were carried out by two independent reviewers (Yi Ming Weng and Min Peng). Discrepancy was resolved by discussion between the two of us. If the two authors could not reach a consensus, another author (Yi Yao) made the decision. The data included first author, publication year, the intervention of experimental treatment and control groups, numbers of enrolled patients in each trial, ORR, major AEs (grade $\geq 3$ ), HR and 95\% CI for PFS (defined as the time from randomization to the first documented disease progression or death), and OS (defined as the time from randomization to death). We tried to obtain additional unpublished data by contacting the primary authors. However, no additional information had been retrieved by us up to now. We assessed the quality of involved randomized controlled clinical trials according to the Cochrane Handbook for Systematic Reviews of Interventions (Version 5.1.0), including sequence generation, allocation concealment, performance bias, detection bias, attrition bias, reporting bias, and other bias. Trial with high risk of bias for any one or more key domains was considered as at "high risk". Trial with low risk of bias for all key domains was considered as at "low risk". Otherwise, it was considered as "unclear".

\section{Data analyses}

Statistical analyses were performed using the RevMan, Version 5.1, and STATA 12.0 software. Stratification analyses were conducted for the following groups: ICI combined chemotherapy vs monotherapy and dual ICIs vs monotherapy. Heterogeneity across studies was assessed using the $Q$-test and $I^{2}$ statistics. Heterogeneity was considered statistically significant when $P<0.05$ or $I^{2}>50 \%$. A fixed-effect model was used when there is no evidence of significant heterogeneity. Otherwise, a random-effect model was applied. Subgroup analysis was conducted to explore the possible sources of heterogeneity. Pooled HR for survival outcomes (PFS and OS) and pooled RR for dichotomous data (ORR, severe AEs) with 95\% CI were calculated by the proper algorithm. $P<0.05$ was regarded as statistically significant, and all $P$-values were two sided.

\section{Results \\ Study characteristics and risk of bias}

Studies were identified as indicated in Figure 1. Characteristics of included trials are listed in Table 1. Overall, 12 RCTs with 3,280 patients in the experimental group and 2,709 controls were included in this meta-analysis. ${ }^{26-28,31-39}$ Five ICIs (pembrolizumab, ipilimumab, nivolumab, atezolizumab, and durvalumab) were studied. All RCTs were conducted for lung cancer. Nine trials enrolled NSCLC patients, and three trials enrolled SCLC patients. Ten trials used ICI with chemotherapy, and two trials used dual ICI. Five trials investigated PD-1 inhibitors, three trials specifically studied PD-L1 inhibitors, and six trials examined CTLA-4 inhibitors. Response was assessed using response evaluation criteria in solid tumors (RECIST) or WHO criteria for all 12 studies. Of the 12 studies in this meta-analysis, 10 were classified as low-risk of bias existed for all key domains, while two trials were deemed high-risk of bias due to their open-label design.

\section{Overall response rate (ORR)}

Twelve studies with 3,280 patients in the experimental arm and 2,709 cases in the control arm met the inclusion criteria and were finally included for ORR analysis. The funnel plots did not demonstrated obvious asymmetry 


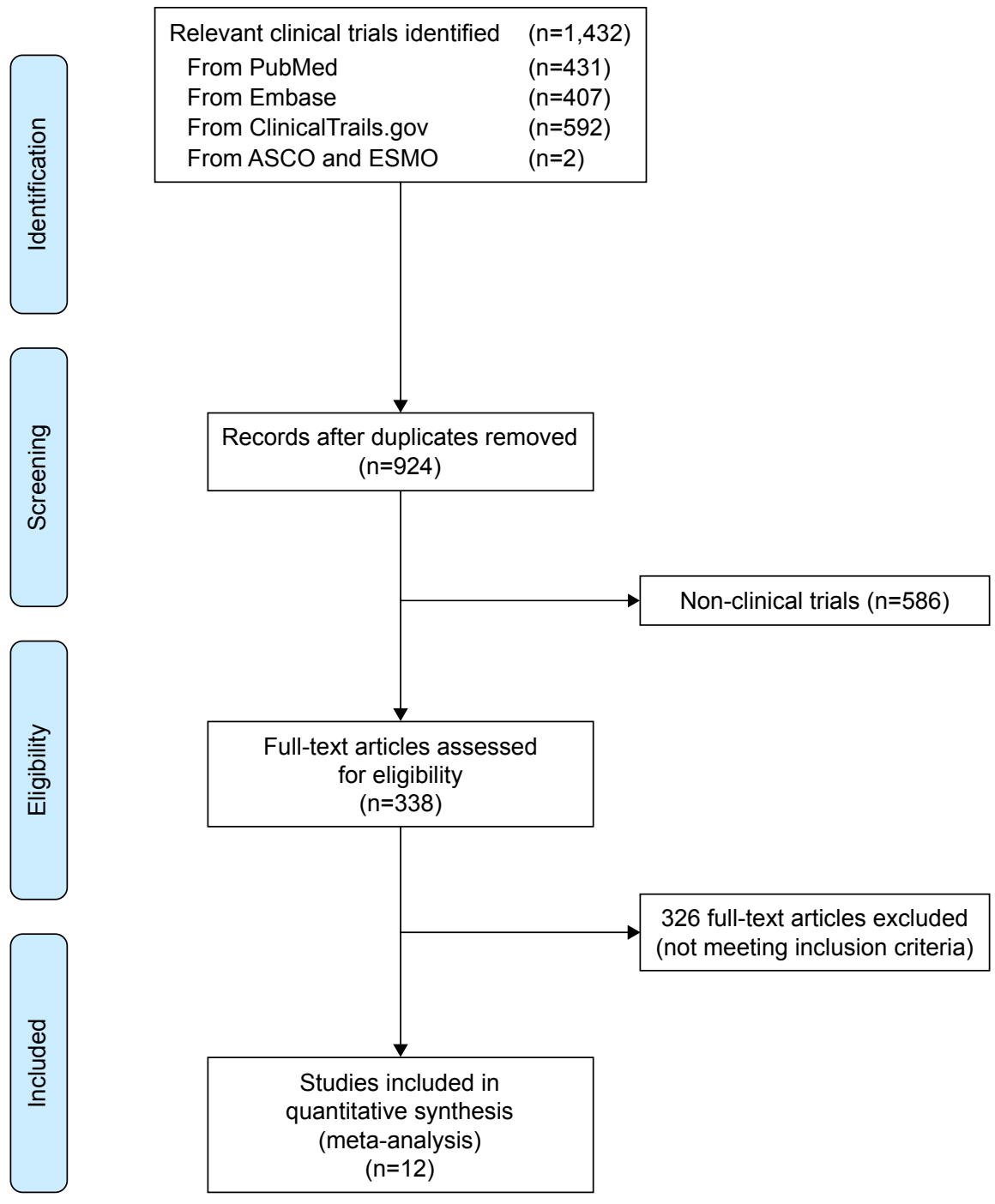

Figure I Flow diagram of included and excluded studies.

for ORR. The heterogeneity between studies was significant $\left(P<0.00001, I^{2}=86 \%\right)$. The pooled RR for ORR was performed using a random-effect model. This meta-analysis showed a significant improvement of ORR in combination ICI therapy ( $\mathrm{RR}=1.44$ [95\% CI 1.19, 1.74], $P=0.0002)$ (Figure 2A). Subgroup analysis according to the tumor type showed that only NSCLC patients had beneficial effects from combination ICI therapy in ORR $(\mathrm{RR}=1.56[95 \% \mathrm{CI}$ $\left.1.25,1.94], P<0.0001, I^{2}=83 \%\right)$. There was also a tendency to improve ORR in SCLC patients though not significant $\left(\mathrm{RR}=1.08\right.$ [95\% CI 0.80, 1.45], $P=0.62, I^{2}=56 \%$ ) (Figure 3A). In subgroup analysis, based on the combination type, significant improvements in ORR were seen in both ICI combined with chemotherapy $(\mathrm{RR}=1.39$ [95\% CI 1.14, 1.70], $P=0.001$, $\left.I^{2}=87 \%\right)$ and dual ICI ( $\mathrm{RR}=1.74$ [95\% CI 1.31, 2.32], $P=0.0001, I^{2}=0 \%$ ) (Figure 3B). Subgroup analysis based on the ICI type showed significant improvements in ORR in PD-1 (RR =2.01 [95\% CI 1.71, 2.37], $\left.P<0.00001, I^{2}=15 \%\right)$ and PD-L1 (RR $=1.38$ [95\% CI 1.22, 1.55], $P<0.00001$, $I^{2}=41 \%$ ) inhibitors (Figure $3 \mathrm{C}$ ). A sensitivity analysis was conducted to further explore the source of heterogeneity. The study conducted by Gandhi et al ${ }^{34}$ showed results that were out of range as compared to the other studies, which likely contributed to the heterogeneity. After excluding this study, heterogeneity was also significant among the remaining studies $\left(P<0.00001, I^{2}=79 \%\right)$ and the result demonstrated that ICI combined therapy had a significant improvement for ORR ( $\mathrm{RR}=1.34$ [95\% CI 1.14, 1.58], $P=0.0005$ ).

\section{PFS}

PFS data were available in 11 trials. The funnel plots did not demonstrate obvious asymmetry for PFS, and the heterogeneity 
Table I Characteristics of the included studies

\begin{tabular}{|c|c|c|c|c|c|c|c|}
\hline \multirow[t]{2}{*}{ Author } & \multirow{2}{*}{$\begin{array}{l}\text { Year of } \\
\text { publication }\end{array}$} & \multirow[t]{2}{*}{ Cancer type } & \multirow[t]{2}{*}{ Intervention } & \multirow[t]{2}{*}{ Cases } & \multirow{2}{*}{$\begin{array}{l}\text { ORR } \\
\text { (event) }\end{array}$} & \multicolumn{2}{|l|}{ HR (95\% Cl) } \\
\hline & & & & & & PFS & OS \\
\hline $\begin{array}{l}\text { Corey J } \\
\text { Langer }\end{array}$ & 2016 & $\begin{array}{l}\text { Nonsquamous } \\
\text { NSCLC }\end{array}$ & $\begin{array}{l}\text { Carboplatin + pemetrexed + pembrolizumab } \\
\text { Carboplatin + pemetrexed + placebo }\end{array}$ & $\begin{array}{l}60 \\
63\end{array}$ & $\begin{array}{l}33 / 60 \\
18 / 63\end{array}$ & $\begin{array}{l}0.53 \\
(0.31-0.91)\end{array}$ & $\begin{array}{l}0.90 \\
(0.42-\mid .91)\end{array}$ \\
\hline $\begin{array}{l}\text { Thomas J } \\
\text { Lynch }\end{array}$ & 2012 & NSCLC & $\begin{array}{l}\text { Ipilimumab + paclitaxel + carboplatin followed } \\
\text { by placebo + paclitaxel + carboplatin } \\
\text { Placebo + paclitaxel + carboplatin followed by } \\
\text { ipilimumab + paclitaxel + carboplatin } \\
\text { Placebo + paclitaxel + carboplatin }\end{array}$ & $\begin{array}{l}70 \\
68 \\
66\end{array}$ & $\begin{array}{l}15 / 70 \\
22 / 68 \\
9 / 66\end{array}$ & $\begin{array}{l}0.88 \\
(0.61-1.27)\end{array}$ & $\begin{array}{l}0.99 \\
(0.67-1.46)\end{array}$ \\
\hline $\begin{array}{l}\text { Ramaswamy } \\
\text { Govindan }\end{array}$ & 2017 & $\begin{array}{l}\text { Squamous } \\
\text { NSCLC }\end{array}$ & $\begin{array}{l}\text { Chemotherapy + ipilimumab } \\
\text { Chemotherapy + placebo }\end{array}$ & 388 & $\begin{array}{l}172 / 388 \\
169 / 361\end{array}$ & $0.87(0.75-1.01)$ & $\begin{array}{l}0.91 \\
(0.77-1.07)\end{array}$ \\
\hline SJ Antonia & 2017 & NSCLC & $\begin{array}{l}\text { Durvalumab + chemoradiotherapy } \\
\text { Placebo + chemoradiotherapy }\end{array}$ & $\begin{array}{l}443 \\
213\end{array}$ & $\begin{array}{l}126 / 443 \\
34 / 213\end{array}$ & \begin{tabular}{|l}
0.52 \\
$(0.42-0.65)$
\end{tabular} & NA \\
\hline MA Socinski & 2018 & $\begin{array}{l}\text { Nonsquamous } \\
\text { NSCLC }\end{array}$ & $\begin{array}{l}\text { Atezolizumab + bevacizumab + carboplatin }+ \\
\text { paclitaxel } \\
\text { Bevacizumab + carboplatin }+ \text { paclitaxel }\end{array}$ & $\begin{array}{l}400 \\
400\end{array}$ & $\begin{array}{l}224 / 353 \\
\mid 59 / 331\end{array}$ & $0.62(0.52-0.74)$ & $\begin{array}{l}0.78 \\
(0.64-0.96)\end{array}$ \\
\hline L Gandhi & 2018 & $\begin{array}{l}\text { Nonsquamous } \\
\text { NSCLC }\end{array}$ & $\begin{array}{l}\text { Pembrolizumab + pemetrexed + cisplatin/ } \\
\text { carboplatin } \\
\text { Placebo + pemetrexed + cisplatin/carboplatin }\end{array}$ & $\begin{array}{l}410 \\
206\end{array}$ & $\begin{array}{l}195 / 410 \\
39 / 206\end{array}$ & $0.52(0.43-0.64)$ & $\begin{array}{l}0.49 \\
(0.38-0.64)\end{array}$ \\
\hline $\begin{array}{l}\text { MD } \\
\text { Hellmann }\end{array}$ & 2018 & NSCLC & $\begin{array}{l}\text { Nivolumab + ipilimumab } \\
\text { Platinum doublet chemotherapy }\end{array}$ & $\begin{array}{l}139 \\
160\end{array}$ & $\begin{array}{l}63 / 139 \\
43 / 160\end{array}$ & $0.58(0.4 \mathrm{I}-0.8 \mathrm{I})$ & \\
\hline $\begin{array}{l}\text { Luis G Paz- } \\
\text { Ares }\end{array}$ & 2018 & $\begin{array}{l}\text { Squamous } \\
\text { NSCLC }\end{array}$ & $\begin{array}{l}\text { Pembrolizumab + carboplatin }+ \text { nab-paclitaxel } \\
\text { Carboplatin + nab-paclitaxel }\end{array}$ & $\begin{array}{l}278 \\
281\end{array}$ & $\begin{array}{l}59 / 101 \\
36 / 103\end{array}$ & $0.56(0.45-0.70)$ & $\begin{array}{l}0.64 \\
(0.49-0.85)\end{array}$ \\
\hline Robert Jotte & 2018 & $\begin{array}{l}\text { Squamous } \\
\text { NSCLC }\end{array}$ & $\begin{array}{l}\text { Atezolizumab }+ \text { carboplatin }+ \text { nab-paclitaxel } \\
\text { Carboplatin }+ \text { nab-paclitaxel }\end{array}$ & $\begin{array}{l}343 \\
340\end{array}$ & $\begin{array}{l}84 / 169 \\
57 / 140\end{array}$ & $0.71(0.60-0.85)$ & $\begin{array}{l}0.96 \\
(0.78-1.18)\end{array}$ \\
\hline $\begin{array}{l}\text { Scott J } \\
\text { Antonia }\end{array}$ & 2016 & $\mathrm{SCLC}$ & $\begin{array}{l}\text { Nivolumab }+ \text { ipilimumab } \\
\text { Nivolumab }\end{array}$ & $\begin{array}{l}118 \\
98\end{array}$ & $\begin{array}{l}24 / 115 \\
10 / 98\end{array}$ & NA & NA \\
\hline Martin Reck & 2016 & SCLC & $\begin{array}{l}\text { Etoposide + platinum (cisplatin or carboplatin) } \\
+ \text { ipilimumab } \\
\text { Etoposide + platinum (cisplatin or carboplatin) } \\
+ \text { placebo }\end{array}$ & $\begin{array}{l}478 \\
476\end{array}$ & $297 / 478$ & $\begin{array}{l}0.85 \\
(0.75-0.97)\end{array}$ & $\begin{array}{l}0.94 \\
(0.8 I-1.09)\end{array}$ \\
\hline Martin Reck & 2013 & SCLC & $\begin{array}{l}\text { Ipilimumab + paclitaxel + carboplatin followed } \\
\text { by placebo + paclitaxel + carboplatin } \\
\text { Placebo + paclitaxel + carboplatin followed by } \\
\text { ipilimumab + paclitaxel + carboplatin } \\
\text { Placebo + paclitaxel + carboplatin }\end{array}$ & $\begin{array}{l}43 \\
42 \\
45\end{array}$ & $\begin{array}{l}14 / 43 \\
24 / 42 \\
22 / 45\end{array}$ & $\begin{array}{l}0.93 \\
(0.59-1.48)\end{array}$ & $\begin{array}{l}0.95 \\
(0.59-1.54)\end{array}$ \\
\hline
\end{tabular}

Abbreviations: NA, not available; NSCLC, non-small-cell lung cancer; ORR, overall response rate; PFS, progression-free survival; RCT, randomized controlled trial; SCLC, small-cell lung cancer.

between studies was significant $\left(P<0.00001, I^{2}=77 \%\right)$. The pooled HR for PFS was performed using random-effect model. A statistically significant improvement in PFS (HR $=0.67[95 \%$ CI 0.59, 0.77], $P<0.00001$ ) was observed in patients receiving combination ICI therapy (Figure 2B). In subgroup analysis, benefits in PFS were obtained from combination ICI therapy in both NSCLC (HR $=0.64$ [95\% CI 0.55, 0.74], $P<0.00001$, $\left.I^{2}=73 \%\right)$ and $\mathrm{SCLC}(\mathrm{HR}=0.86$ [95\% CI 0.76, 0.97], $P=0.02$,
$I^{2}=0 \%$ ) (Figure 4A). Besides, significant improvements in PFS were seen in both ICI combined with chemotherapy ( $\mathrm{HR}=0.68$ [95\% CI 0.59, 0.79], $\left.P<0.00001, I^{2}=79 \%\right)$ and dual ICI (HR $=0.58$ [95\% CI 0.41, 0.81], $P=0.002)$ (Figure 4B). In subgroup analysis, based on the ICI type, significant improvements in PFS were seen in all ICI: PD-1 (HR $=0.55$ [95\% CI 0.48, 0.62], $P<0.00001, I^{2}=0 \%$ ), PD-L1 (HR $=0.62[95 \%$ CI $0.52,0.73], P<0.00001, I^{2}=59 \%$, and CTLA-4 $(\mathrm{HR}=0.83$ 


\section{A}

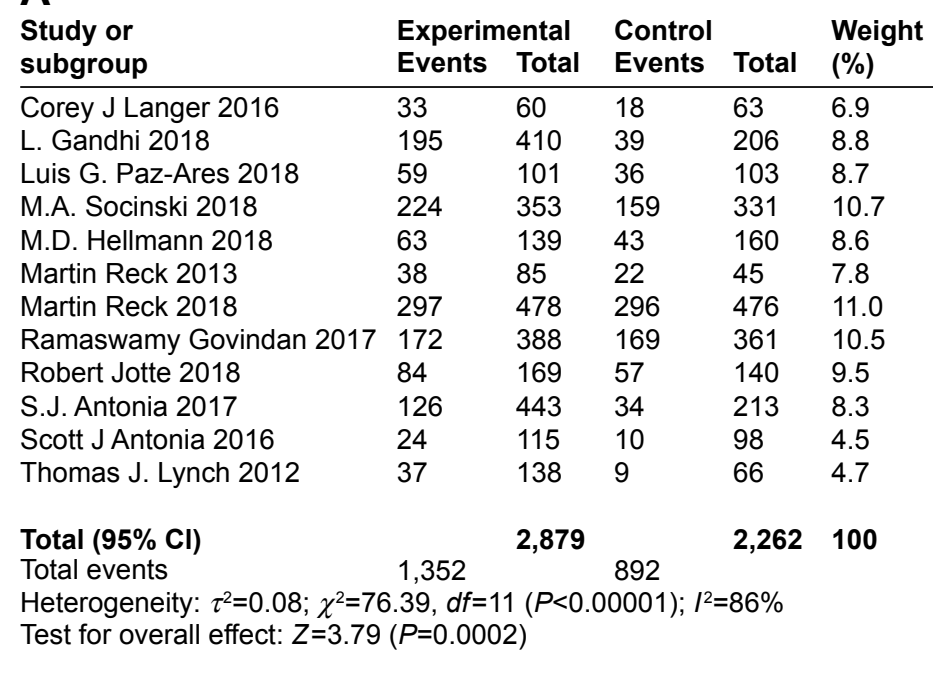

B

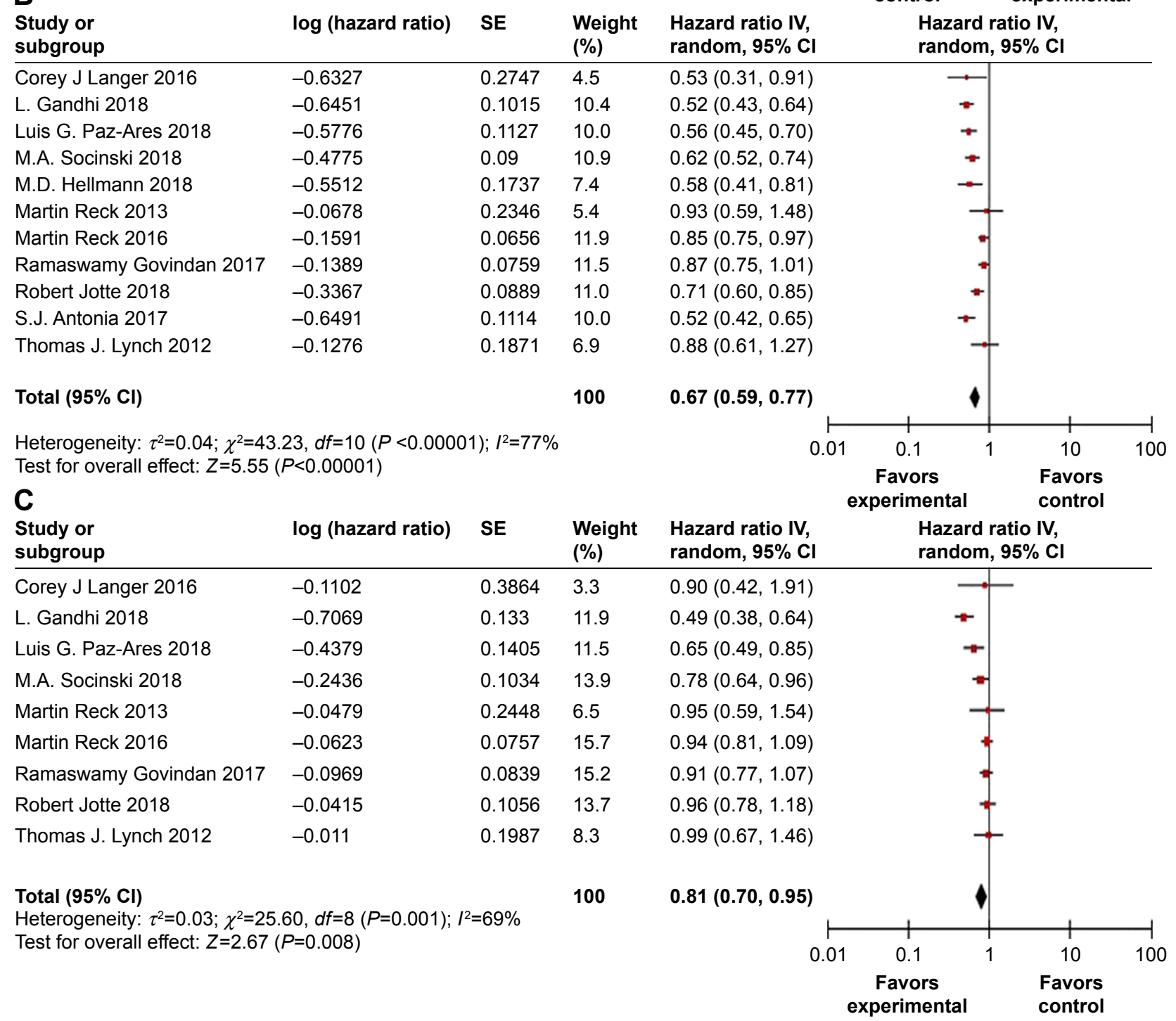

Figure 2 Meta-analysis of ORR, PFS, and OS.

Note: (A) ORR, (B) PFS, and (C) OS.

Abbreviations: ORR, overall response rate; PFS, progression-free survival. 
A

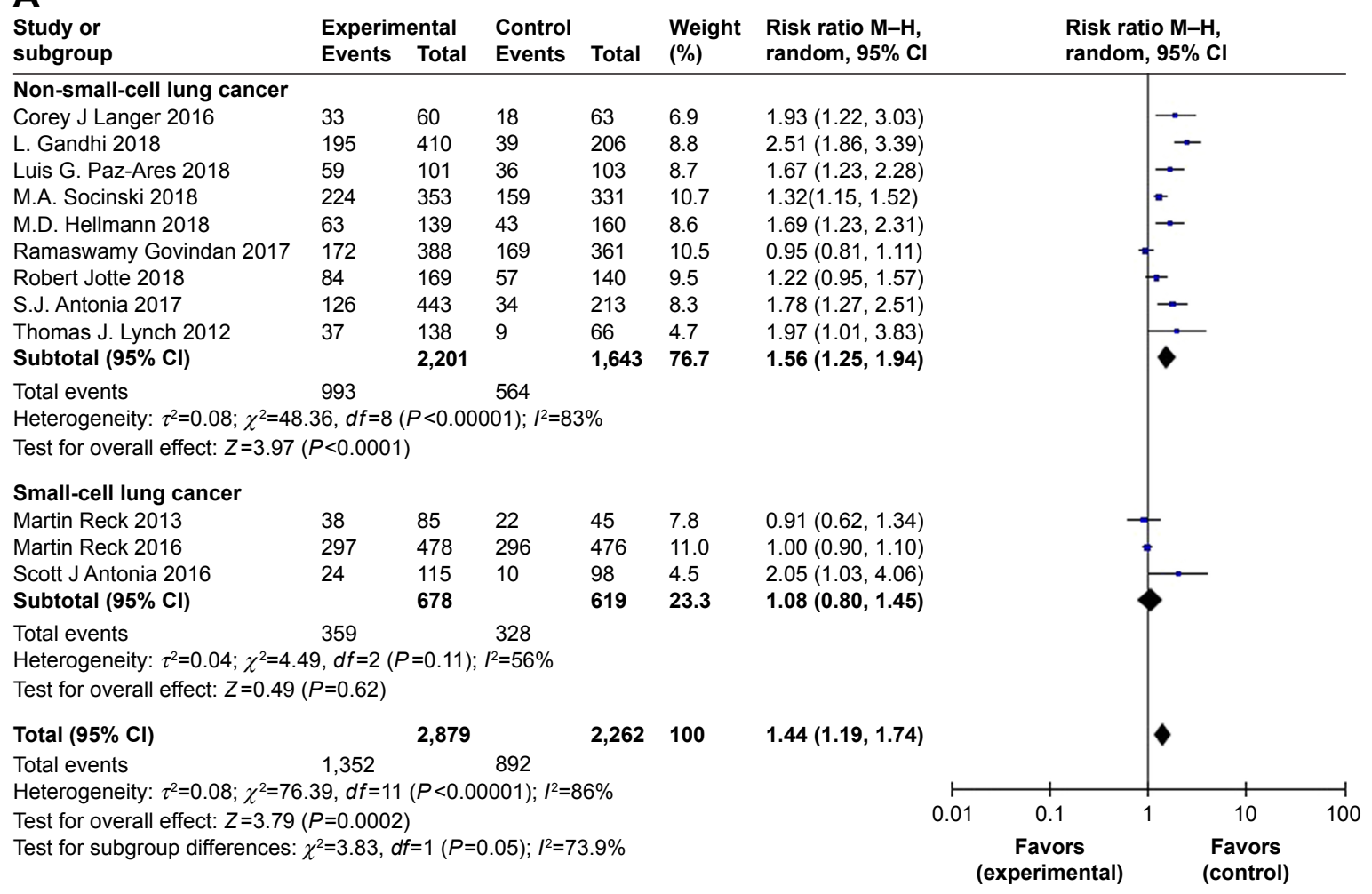

B

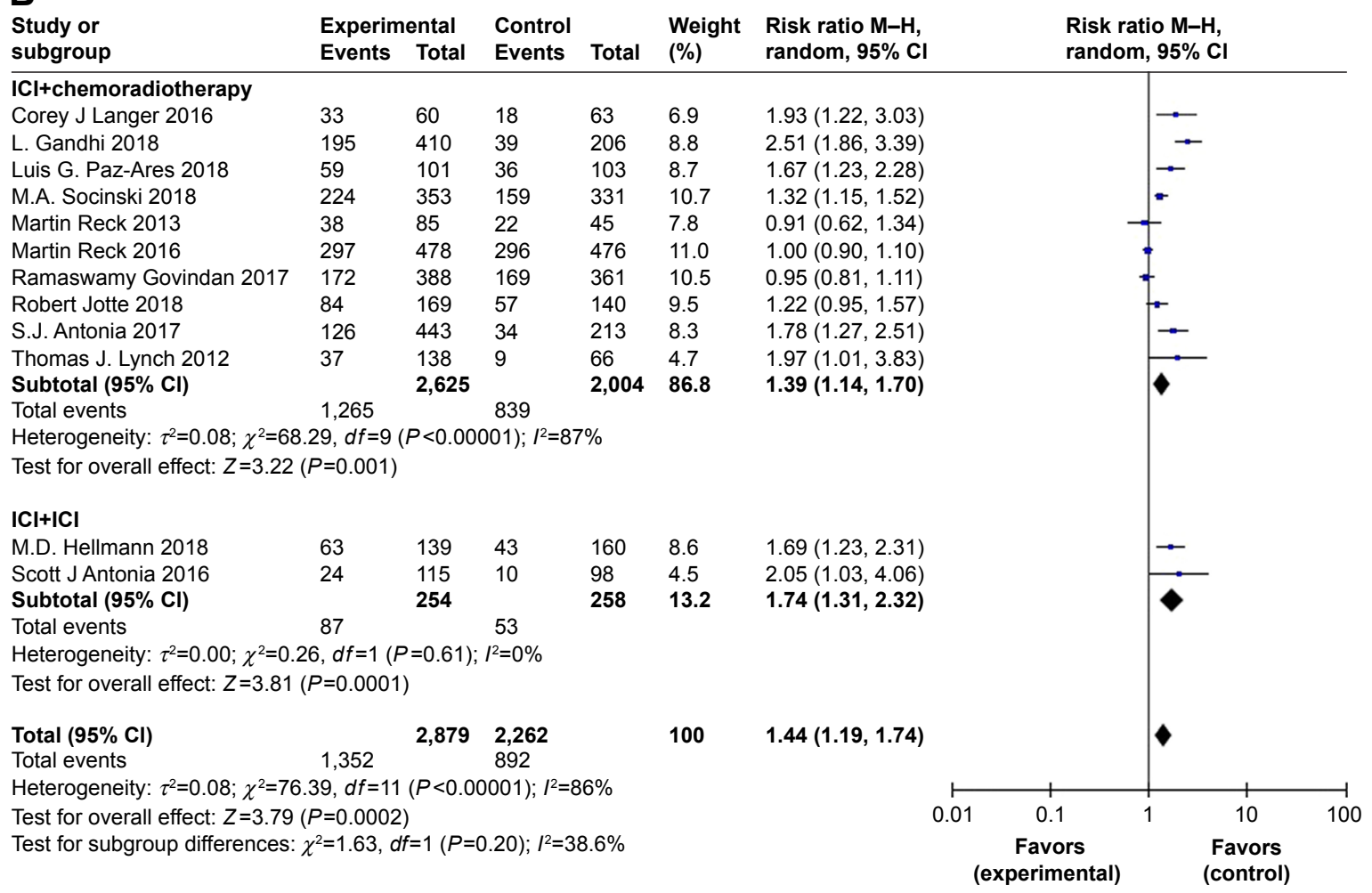

Figure 3 (Continued) 


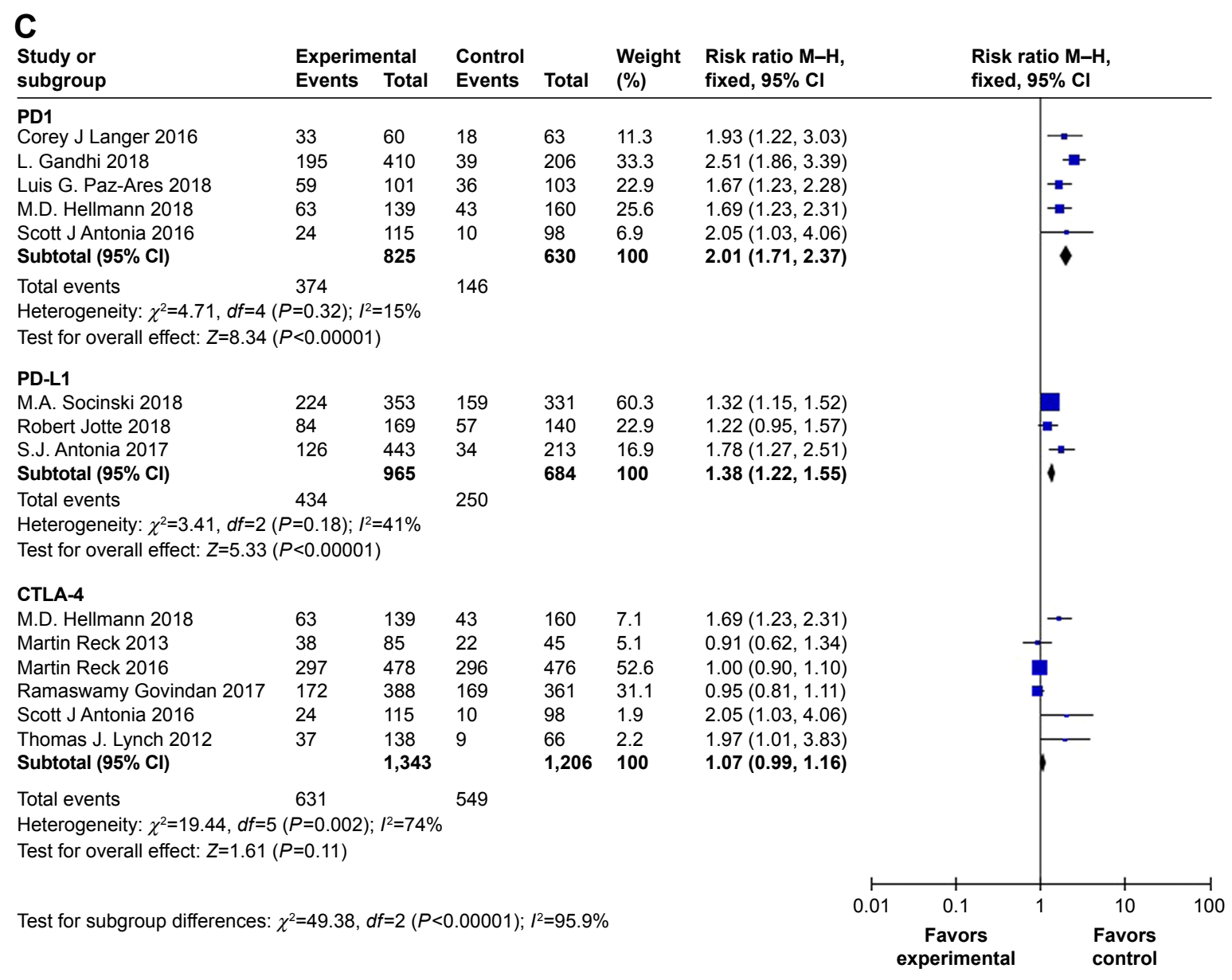

Figure 3 Subgroup analysis of ORR.

Note: (A) Based on the tumor type, (B) based on the combination type, and $(\mathbf{C})$ based on the $\mathrm{ICl}$ type.

Abbreviations: $\mathrm{ICl}$, immune checkpoint inhibitor; ORR, overall response rate.

A

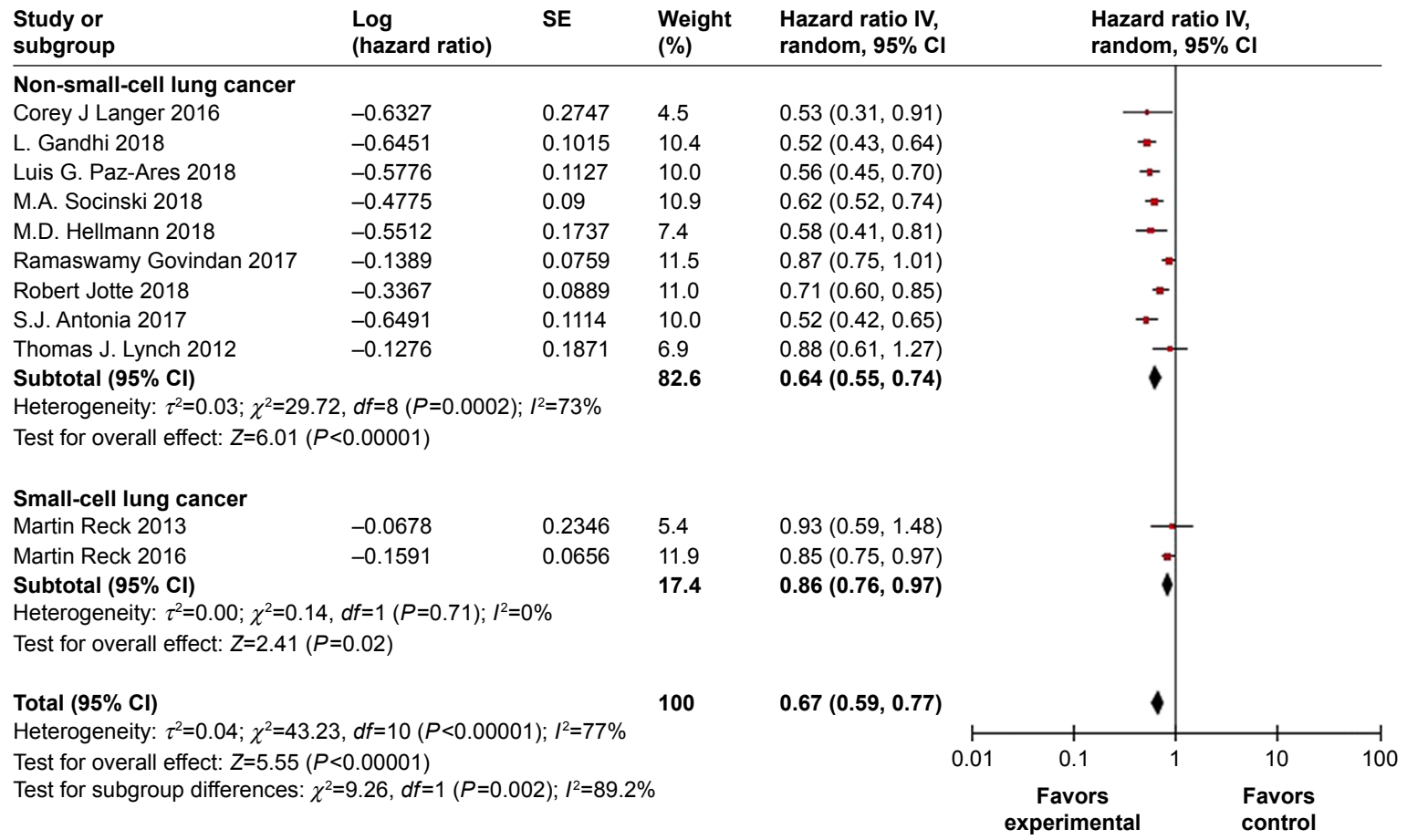

Figure 4 (Continued) 
B

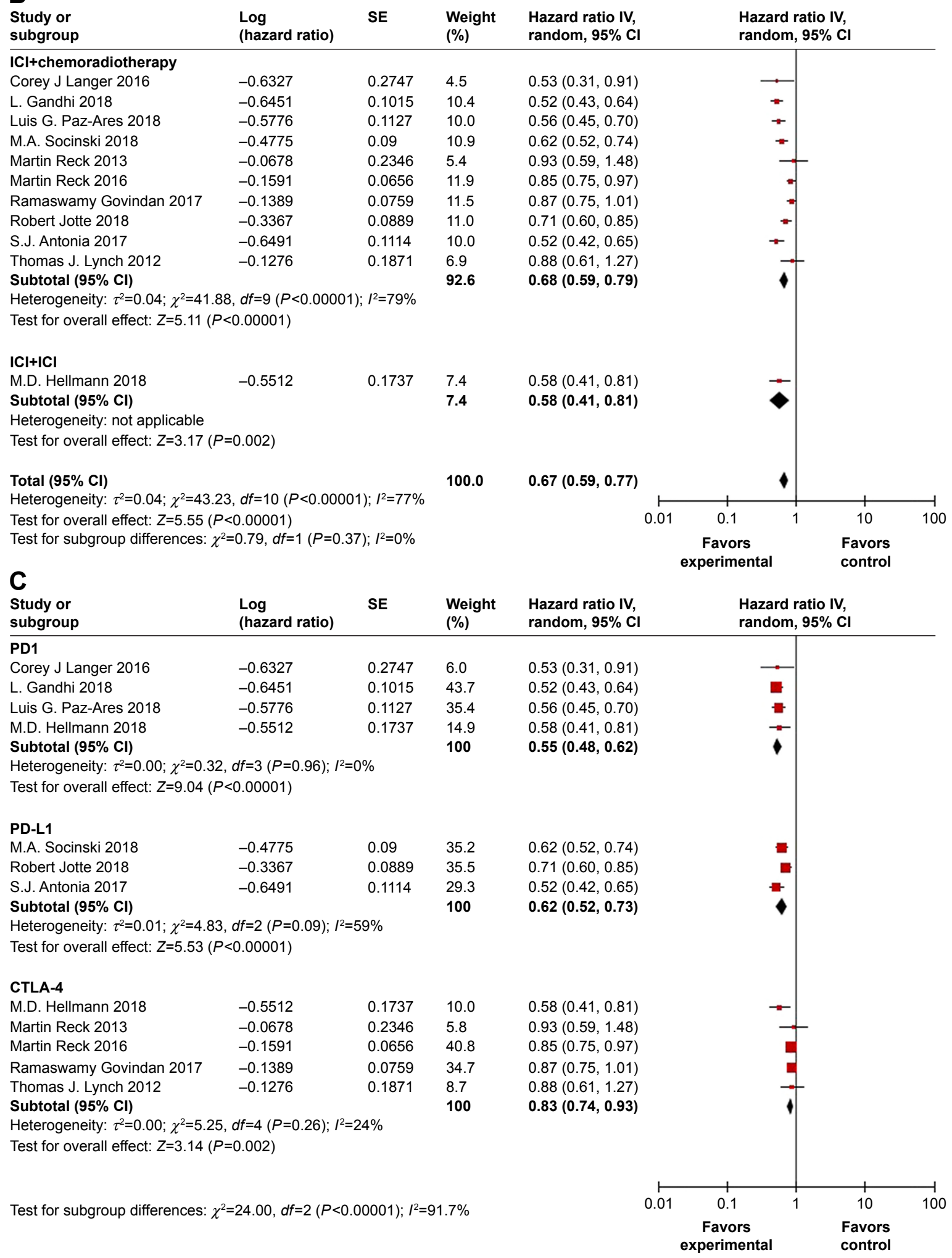

Figure 4 Subgroup analysis of PFS.

Note: (A) Based on the tumor type, (B) based on the combination type, and (C) based on the $\mathrm{ICl}$ type.

Abbreviations: $\mathrm{ICl}$, immune checkpoint inhibitor; PFS, progression-free survival. 
[95\% CI 0.74, 0.93], $P=0.002, I^{2}=24 \%$ ) (Figure 4C). The sensitivity analysis was conducted by excluding each study in a step-wise manner. Data suggested that results from Reck et $\mathrm{al}^{26}$ likely contributed to the heterogeneity. After excluding this study, heterogeneity was also significant among the remaining studies $\left(P=0.0002, I^{2}=72 \%\right)$ and the result demonstrated that ICI combined therapy had a significant improvement for PFS (HR $=0.65$ [95\% CI 0.56, 0.75], $P<0.00001)$.

\section{A}

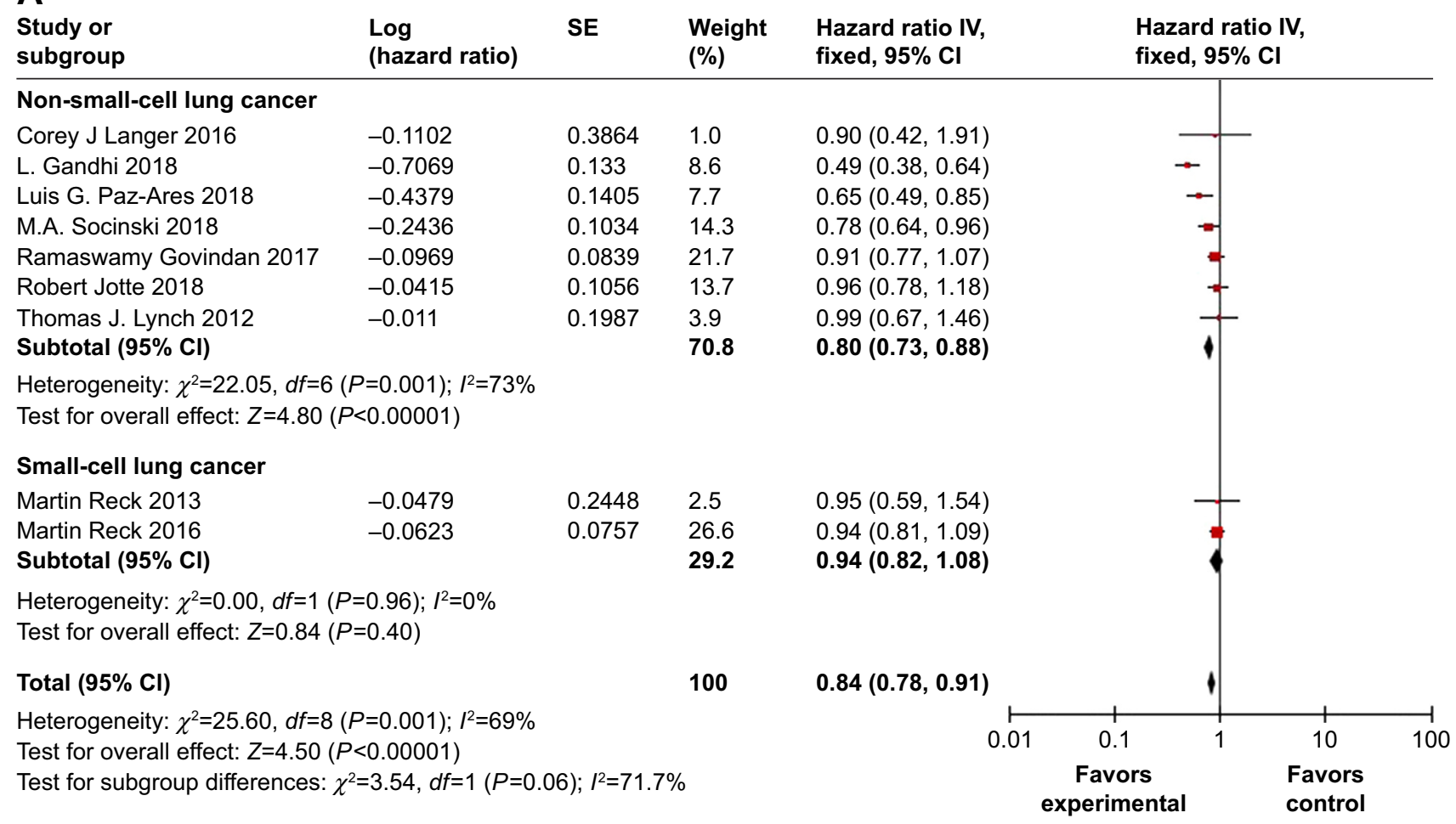

B

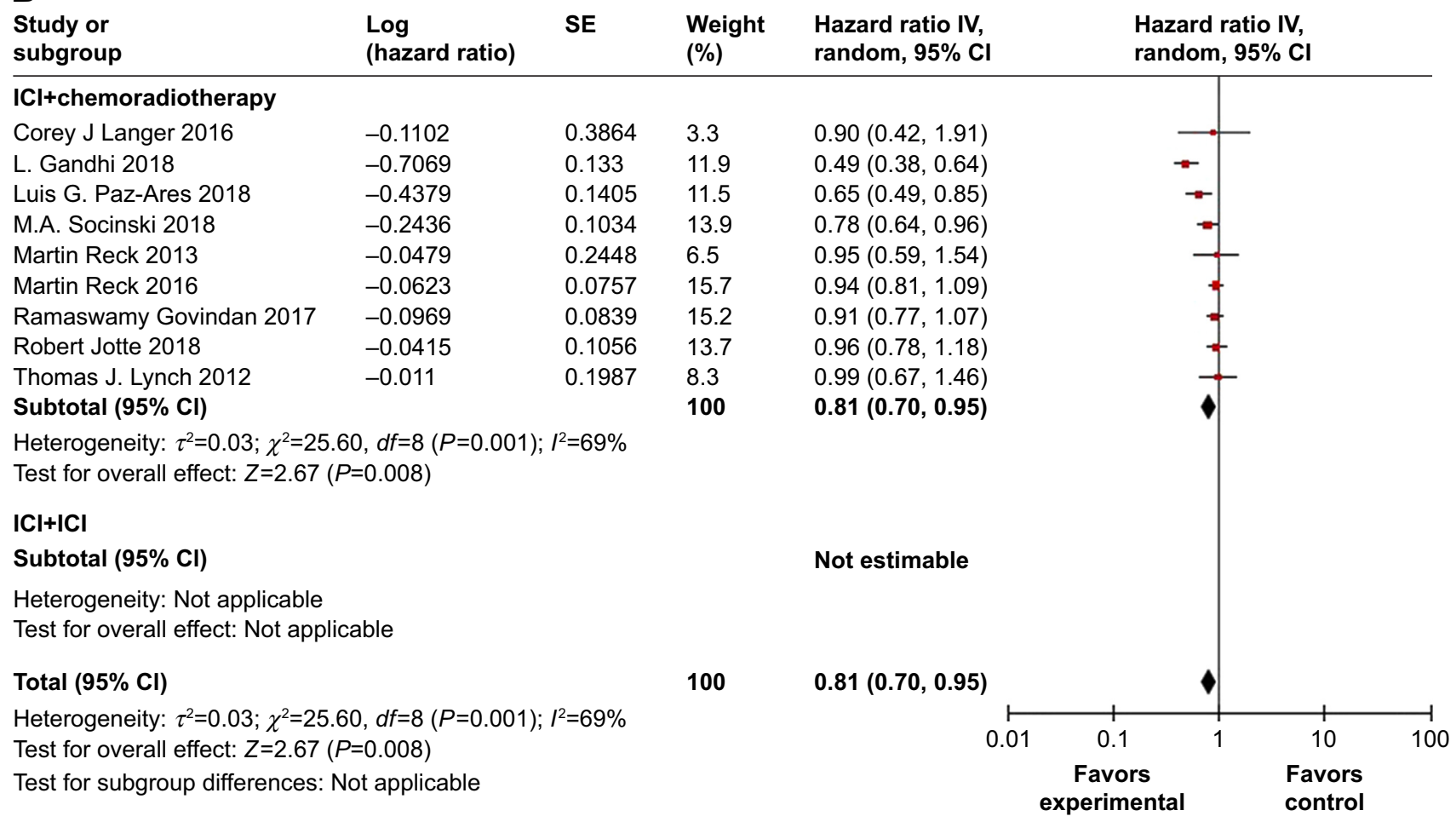

Figure 5 (Continued) 


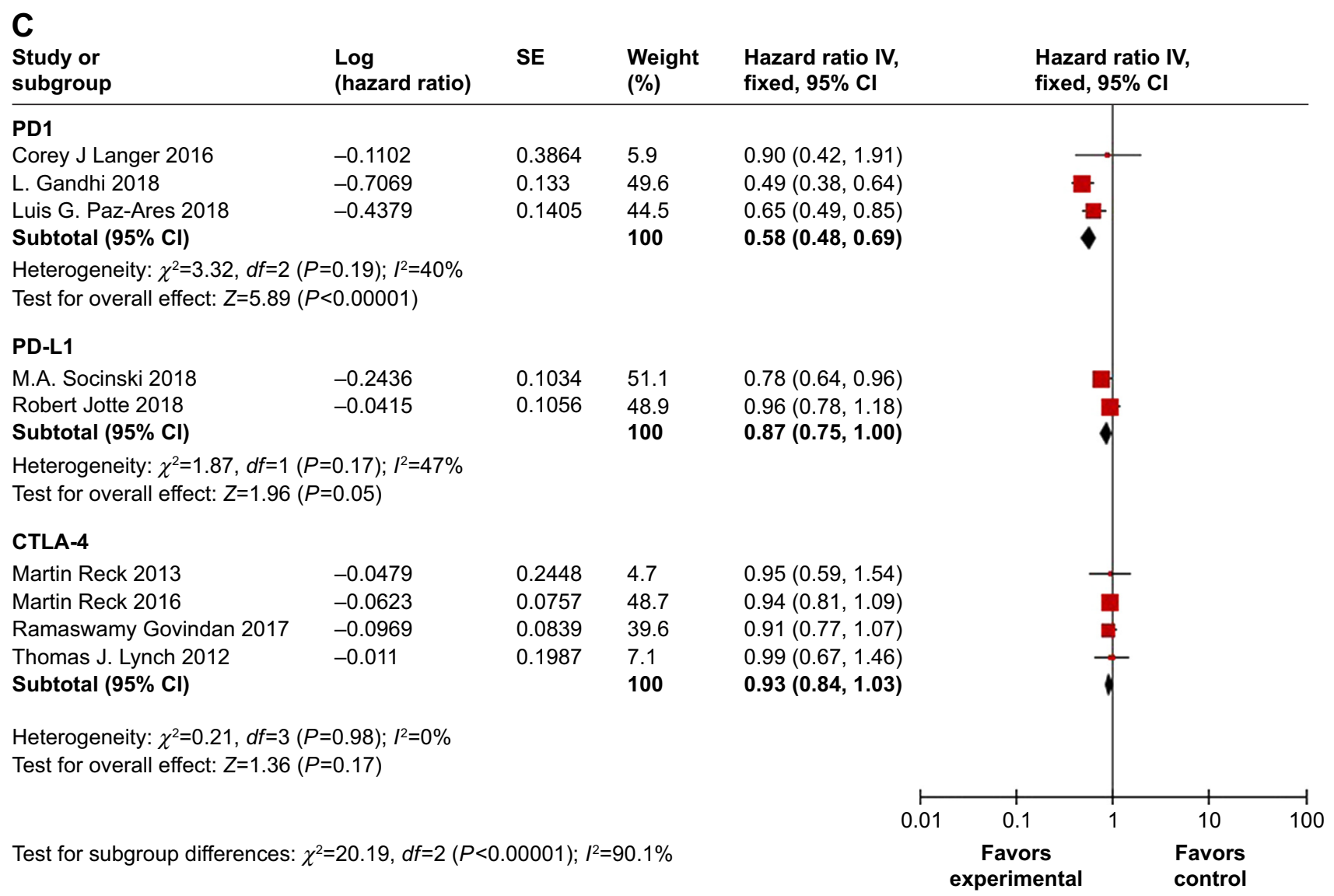

Figure 5 Subgroup analysis of OS.

Note: (A) Based on the tumor type, (B) based on the combination type, and (C) based on the ICl type.

Abbreviation: $\mathrm{ICl}$, immune checkpoint inhibitor.

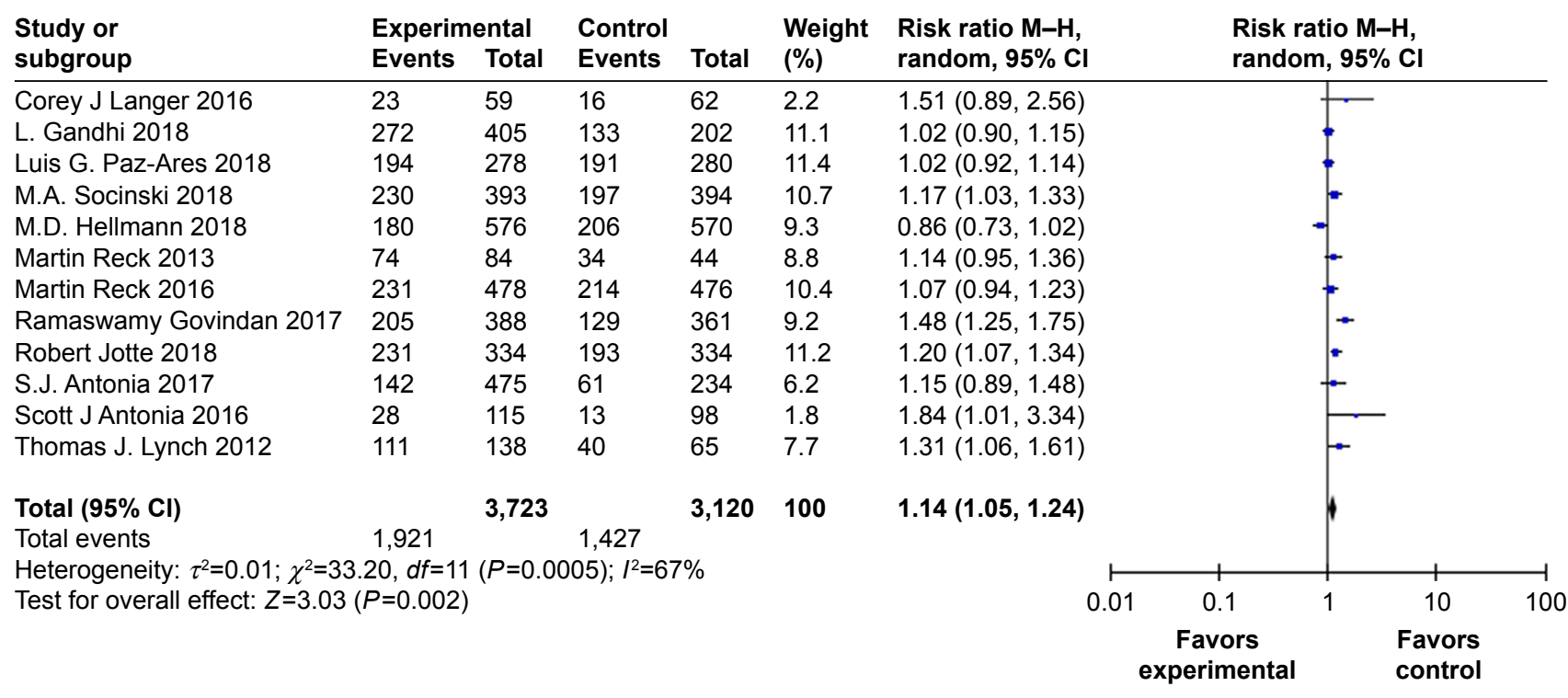

Figure 6 Meta-analysis of grade $\geq 3$ AEs.

Abbreviation: AEs, adverse events. 


\section{OS}

Nine studies reported OS data. The funnel plots did not demonstrate obvious asymmetry for OS, and the heterogeneity between studies was significant $\left(P=0.001, I^{2}=69 \%\right)$. The pooled HR for OS was performed using a random-effect model. In the pooled analyses, combination ICI therapy had a significant improvement in OS (HR $=0.81$ [95\% CI 0.70, 0.95], $P=0.008$ ) (Figure 2C). Subgroup analysis based on the tumor type showed that significant improvements in OS from combination ICI therapy were achieved in only NSCLC patients $(\mathrm{HR}=0.80$ [95\% CI 0.73, 0.88], $P<0.00001$, $\left.I^{2}=73 \%\right)$. However, no statistically significant improvement in OS was observed for patients with SCLC (HR $=0.94$ [95\% CI $0.82,1.08], P=0.40, I^{2}=0 \%$ ) (Figure $5 \mathrm{~A}$ ). In subgroup analysis, based on the combination type, significant improvements in OS were seen in ICI combined with chemotherapy (HR $=0.81$ [95\% CI 0.70, 0.95], $P=0.008$ ) (Figure 5B). Subgroup analysis based on the ICI type showed that only PD-1 inhibitors had significant improvements in OS and no heterogeneity was detected (HR $=0.58$ [95\% CI 0.48 , 0.69 ], $P<0.00001, I^{2}=40 \%$ ). There was also a tendency to improve OS in PD-L1 inhibitors (HR $=0.87$ [95\% CI 0.75, $1.00], P=0.05, I^{2}=47 \%$ ). However, no statistically significant improvement in OS was observed for CTLA-4 inhibitors $\left(\mathrm{HR}=0.93\right.$ [95\% CI 0.84, 1.03], $P=0.17, I^{2}=0 \%$ ) (Figure 5C). The sensitivity analysis was conducted by excluding each study in a step-wise manner, and the data again suggested that results from Gandhi et al ${ }^{13}$ likely contributed to the heterogeneity. After excluding this study, heterogeneity was insignificant among the remaining studies $\left(P=0.32, I^{2}=14 \%\right)$ and the result demonstrated that ICI combined therapy had a significant improvement for OS (HR $=0.88$ [95\% CI 0.80, 0.96], $P=0.005)$.

\section{AEs}

Data for the grade $\geq 3$ AEs were available in all 12 studies. The incidences of grade $\geq 3$ AEs from combination ICI therapy were higher ( $\mathrm{RR}=1.14$ [95\% CI 1.05, 1.24], $P=0.002, I^{2}=67 \%$ ) (Figure 6). In subgroup analysis, based on the ICI type, there were more incidences of grade $\geq 3 \mathrm{AEs}$ ( $\mathrm{RR}=1.18$ [95\% CI 1.09, 1.28], $P<0.0001, I^{2}=0 \%$ ) in the PD-L1 inhibitors' therapy group. There was also a tendency to improve incidences of grade $\geq 3$ AEs in CTLA- 4 inhibitors $\left(\mathrm{RR}=1.18\right.$ [95\% CI 0.99, 1.41], $\left.P=0.06, I^{2}=80 \%\right)$. However, no statistically significant improvement in incidences of grade $\geq 3$ AEs was observed for PD-1 inhibitors ( $R R=1.03$ [95\% CI 0.90, 1.18], $P=0.70, I^{2}=58 \%$ ). Patients receiving combination ICI therapy had a significantly higher risk of fatigue ( $\mathrm{RR}=1.54$ [95\% CI 1.09, 2.17], $P=0.01, I^{2}=22 \%$ ).
In subgroup analysis, based on the ICI type, only CTLA-4 inhibitors had a significantly higher risk of fatigue $(\mathrm{RR}=1.57$ [95\% CI 1.01, 2.44], $P=0.04, I^{2}=22 \%$ ). Combination ICI therapy was associated to a significantly increased risk of grade $\geq 3$ increased transaminases $(\mathrm{RR}=3.43$ [95\% CI 1.23, 9.56], $\left.P=0.02, I^{2}=29 \%\right)$. Subgroup analysis based on the ICI type showed that only PD-L1 inhibitors had a significantly higher risk of grade $\geq 3$ increased transaminases $(\mathrm{RR}=4.70$ [95\% CI 1.57, 14.04], $P=0.006$ ). While, there was no difference in the incidences of pneumonitis ( $\mathrm{RR}=1.60$ [95\% CI $0.84,3.03], P=0.15, I^{2}=0 \%$ ).

\section{Discussion}

ICIs, which target regulatory pathways in T cells to enhance antitumor immune response, have offered significant clinical benefits against cancer. ${ }^{4,7}$ Nevertheless, some gene and environment factors of tumors play a critical role in the suppressive immune function, compromising the efficacy of immunotherapy. ${ }^{40-45}$ Combination therapy with ICI and nanoparticle drug formulations give cancer patients more options for disease control and perhaps a cure. ${ }^{3,24,46}$ Even so, whether combination therapy with ICI is beneficial for lung cancer, and which patient subgroups may benefit from this strategy, remains unclear. Long-term outcomes and large clinical trials have been lacking in previous meta-analysis, which demonstrated that ICI combination therapy had no improvement in OS in lung cancer..$^{30}$ Outcomes of trials for lung cancer using combination ICI therapy have only been published recently, and the clinical value of combination ICI therapy is still controversial. The objective of our meta-analysis was to integrate all data from relevant trials to address this controversy.

\section{Main findings}

Our meta-analysis of currently available data provided reliable evidence that combination ICI therapy was associated with significantly higher ORR, PFS, and OS than traditional therapy or monotherapy in lung cancer. However, combination strategies with ICI were related with more treatmentrelated grade $\geq 3 \mathrm{AEs}$, fatigue, and increased transaminases. Nonetheless, combination ICI therapy was a promising treatment for lung cancer.

The classification of lung cancer is based on histological characteristics, and it is mainly divided into the following two subtypes: NSCLC, accounting for $85 \%$ of lung cancer cases, and small-cell lung cancer (SCLC). ${ }^{1}$ The clinical and biological characteristics of the two pathological types are different. In subgroup analysis, based on the tumor type, there was a significant difference of ORR, PFS, and OS between NSCLC and SCLC. Specifically, NSCLC patients 
were associated with better ORR, PFS, and OS, while there was no significant improvement in ORR and OS in SCLC. This indicated that combination ICI therapy should be taken into account in clinical practice and future study designs for NSCLC patients.

The influence of CTLA-4 on T-cell activity primarily occurs in the priming phase of T-cell activation. PD-1/ PD-L1 mediates the induction of anergy and apoptosis of activated $\mathrm{T}$ cells and tumor resistance to the cytotoxic $\mathrm{T}$-cell response. Chemotherapy regulates the composition and function of tumor-infiltrating lymphoid and myeloid cells. Thus, the effect of combination of ICI and chemotherapy was different from dual ICI. ${ }^{9,13,14}$ Subgroup analysis based on combination type showed no obvious difference between ICI plus chemotherapy and dual ICI groups. Both treatment strategies had significant improvements in ORR and PFS. Besides, ICI combined with chemotherapy had significant improvements in OS. Combination treatments with PD-1/PD-L1 inhibitors plus chemotherapy or a CTLA-4 inhibitor are promising treatment options for lung cancer.

PD-1 and PD-L1 inhibitors are reported to be superior to docetaxel in the salvage setting for lung cancer, with improved survival outcomes. There has been speculation that because monoclonal antibodies against PD-L1 still allow the interaction of PD-1 with its other ligand, PD-L2, this could lead to less blockade of the negative inhibitory signal and result in reduced autoimmunity. The functions of PD-1 and CTLA-4 in inhibiting immune responses such as antitumor responses are different. In particular, comparison of PD-1 vs PD-L1 vs CTLA-4 inhibitors is of immense clinical interest. ${ }^{14}$ In subgroup analysis based on ICI type, only PD-1 inhibitors had significant improvements in OS. There was also a tendency to improve OS in PD-L1 inhibitors. However, no statistically significant improvement in OS was observed for CTLA-4 inhibitors.

Compared with traditional therapy or monotherapy, the incidences of grade $\geq 3$ AEs, fatigue, and increased transaminases from combination ICI therapy were higher. Subgroup analysis based on the ICI type showed that PD-1 inhibitors had an improved safety profile overall than PD-L1 and CTLA-4 inhibitors in combination therapy. There was no significant improvement in grade $\geq 3$ AEs, fatigue, and increased transaminases in the PD-1 group.

\section{Agreement/disagreement with previous meta-analyses}

To the best of our knowledge, only one previous metaanalysis has investigated the efficacy of combination
anti-PD-1/PD-L1 and anti-CTLA-4 antibodies or chemotherapy in lung cancer. ${ }^{30}$ That previous meta-analysis included 1,514 patients, and most trials were Phase I/II nonrandomized studies with small sample sizes. Besides, most of the research involved was single-arm studies and no randomization or blinding was used. Nevertheless, that previous study found significant improvement in PFS but not in OS for lung cancer. ${ }^{30}$ Herein, in the current meta-analysis, there were significant improvements in ORR, PFS, and OS in combination ICI therapy for lung cancer. Furthermore, our subgroup analyses based on the tumor type showed that combination ICI therapy significantly improved the OS of NSCLC patients, while no apparent benefit was seen for SCLC in OS. The failure of improvement in OS for SCLC might due to a limited number of studies and the short follow-up time in some trials. Previous meta-analysis summarized PD-1 and PD-L1 inhibitors, dual ICI, and ICI plus chemotherapy in one analysis, which might be the source of heterogeneity. In our subgroup analysis, there was a significant difference of efficacy and safety between PD-1, PD-L1, and CTLA-4 inhibitors.

In terms of the adverse effects, our results differed from those reported in the previous study. The previous metaanalysis focused on the safety of PD-1/PD-L1 inhibitors in lung cancer and showed that the toxicity and efficacy profiles of PD-1 and PD-L1 inhibitors appeared to be similar. ${ }^{47-49}$ However, our study found that PD-1 inhibitors had an improved safety profile as compared to PD-L1 and CTLA-4 inhibitors in combination ICI therapy for lung cancer. The results provided useful information for clinicians for wellbalanced discussions on the risks and benefits of combination ICI therapy in lung cancer.

\section{Limitations}

Our meta-analysis has some limitations, such as a limited number of complete RCTs. For this emerging area of research, many studies assessing combination therapy with ICI are currently ongoing (IMpower 132, IMpower 131, NEPTUNE, and CheckMate 227). In addition, heterogeneity was significant in the analysis of ORR and PFS. However, we minimized heterogeneity influence by using the randomeffects model and performed exploratory subgroup analyses and sensitivity analyses. The different types, doses, frequencies of administration of ICI, and chemotherapy might be the source of heterogeneity. Besides, the inconformity between studies causes limited clinical guidance significance. Finally, two trials used an open-label design, which might result in biased outcomes. Further study of updated information is still required. 


\section{Conclusion}

Our meta-analysis found that combination ICI therapy showed significant benefits in ORR, PFS, and OS for NSCLC. Both combinations of ICI with chemotherapy and dual ICI were effective and relatively safe. PD-1 inhibitors were more effective and appeared safer than PD-L1 and CTLA-4 inhibitors in combination ICI therapy for lung cancer patients. Combination ICI therapy should be taken into account in clinical practice and future study designs for NSCLC patients. While our meta-analysis showed a tendency of improvement in survival for SCLC patients, the current data of our analyses do not appear to support a large-scale clinical application of combination ICI therapy in SCLC patients. Nonetheless, numerous RCTs assessing the efficacy and safety of combination therapy with ICI are currently ongoing, which might address these issues. Emerging evidence suggests that tumor-associated fibroblasts (CAF) can modulate the immunosuppression of TME through diverse mechanisms, thereby compromising the efficacy of immunotherapy. Many treatments for cancer, especially aiming at CAF, continue to evolve. Therefore, with regard to future clinical application, the combination of treating CAF with individualized therapy would be more promising. ${ }^{43}$

\section{Data availability statement}

All data are fully available within the paper without restriction.

\section{Acknowledgments}

The authors thank the reviewers for their helpful comments on this article. This study was funded by National Natural Science Foundation of China (NNSFC) (81670123 and 81770169) and Hubei Province health and family planning scientific research project (WJ2017Q007). The authors thank LetPub (http://www.letpub.com) for its linguistic assistance during the preparation of this article.

\section{Disclosure}

The authors report no conflicts of interest in this work.

\section{References}

1. Torre LA, Bray F, Siegel RL. Global cancer statistics, 2012. CA Cancer J Clin. 2015;65(2):87-108.

2. Toschi L, Rossi S, Finocchiaro G, Santoro A. Non-small cell lung cancer treatment (r)evolution: ten years of advances and more to come. Ecancermedicalscience. 2017;11(11):787.

3. Sharma P, Allison JP. The future of immune checkpoint therapy. Science. 2015;348(6230):56-61.

4. Gubin MM, Zhang X, Schuster H, et al. Checkpoint blockade cancer immunotherapy targets tumour-specific mutant antigens. Nature. 2014;515(7528):577-581.

5. Pardoll DM. The blockade of immune checkpoints in cancer immunotherapy. Nat Rev Cancer. 2012;12(4):252-264
6. Postow MA, Callahan MK, Wolchok JD. Immune Checkpoint Blockade in Cancer Therapy. J Clin Oncol. 2015;33(17):1974-1982.

7. La-Beck NM, Jean GW, Huynh C, Alzghari SK, Lowe DB. Immune Checkpoint Inhibitors: New Insights and Current Place in Cancer Therapy. Pharmacotherapy. 2015;35(10):963-976.

8. Xia B, Herbst RS. Immune checkpoint therapy for non-small-cell lung cancer: an update. Immunotherapy. 2016. 2016;8(3):279-298.

9. Cho JH. Immunotherapy for Non-small-cell Lung Cancer: Current Status and Future Obstacles. Immune Netw. 2017;17(6):378-391.

10. Kroemer G, Galluzzi L. Combinatorial immunotherapy with checkpoint blockers solves the problem of metastatic melanoma-An exclamation sign with a question mark. Oncoimmunology. 2015;4(7):e1058037.

11. Sharma P, Allison JP. Immune checkpoint targeting in cancer therapy: toward combination strategies with curative potential. Cell. 2015; 161(2):205-214.

12. Zhuansun Y, Huang F, Du Y, Lin L, Chen R, Li J. Anti-PD-1/PD-L1 antibody versus conventional chemotherapy for previously-treated, advanced non-small-cell lung cancer: a meta-analysis of randomized controlled trials. J Thorac Dis. 2017;9(3):655-665.

13. Lazzari C, Karachaliou N, Bulotta A, et al. Combination of immunotherapy with chemotherapy and radiotherapy in lung cancer: is this the beginning of the end for cancer? Ther Adv Med Oncol. 2018; 10:1758835918762094.

14. Chae YK, Arya A, Iams W, et al. Current landscape and future of dual anti-CTLA4 and PD-1/PD-L1 blockade immunotherapy in cancer; lessons learned from clinical trials with melanoma and non-small cell lung cancer (NSCLC). J Immunother Cancer. 2018;6(1):39.

15. Curran MA, Montalvo W, Yagita H, Allison JP. PD-1 and CTLA-4 combination blockade expands infiltrating $\mathrm{T}$ cells and reduces regulatory T and myeloid cells within B16 melanoma tumors. Proc Natl Acad Sci U S A. 2010;107(9):4275-4280.

16. Remon J, Pardo N, Martinez-Martí A, et al. Immune-checkpoint inhibition in first-line treatment of advanced non-small cell lung cancer patients: Current status and future approaches. Lung Cancer. 2017; 106(106):70-75.

17. Rizvi NA, Hellmann MD, Snyder A, et al. Cancer immunology. Mutational landscape determines sensitivity to PD-1 blockade in non-small cell lung cancer. Science. 2015;348(6230):124-128.

18. Das R, Verma R, Sznol M, et al. Combination therapy with anti-CTLA-4 and anti-PD-1 leads to distinct immunologic changes in vivo. J Immunol. 2015;194(3):950-959.

19. Gettinger S, Rizvi N, Chow L, et al. OA03.01 First-Line Nivolumab Monotherapy and Nivolumab plus Ipilimumab in Patients with Advanced NSCLC: Long-Term Outcomes from CheckMate 012. J Thorac Oncol. 2017;12(1):S250-S251.

20. Hellmann MD, Rizvi NA, Goldman JW, et al. Nivolumab plus ipilimumab as first-line treatment for advanced non-small-cell lung cancer (CheckMate 012): results of an open-label, phase 1, multicohort study. Lancet Oncol. 2017;18(1):31-41.

21. Hellmann M, Antonia S, Ponce S, et al. MA09.05 Nivolumab Alone or with Ipilimumab in Recurrent Small Cell Lung Cancer (SCLC): 2-Year Survival and Updated Analyses from the Checkmate 032 Trial. J Thorac Oncol. 2017;12(1):S393-S394.

22. Liu WM, Fowler DW, Smith P, Dalgleish AG. Pre-treatment with chemotherapy can enhance the antigenicity and immunogenicity of tumours by promoting adaptive immune responses. Br J Cancer. 2010; 102(1):115-123.

23. Peng J, Hamanishi J, Matsumura N, et al. Chemotherapy Induces Programmed Cell Death-Ligand 1 Overexpression via the Nuclear FactorkappaB to Foster an Immunosuppressive Tumor Microenvironment in Ovarian Cancer. Cancer Res. 2015;75(23):5034-5045.

24. Jure-Kunkel M, Masters G, Girit E, et al. Synergy between chemotherapeutic agents and CTLA-4 blockade in preclinical tumor models. Cancer Immunol Immunother. 2013;62(9):1533-1545.

25. Kanda S, Goto K, Shiraishi H, et al. Safety and efficacy of nivolumab and standard chemotherapy drug combination in patients with advanced non-small-cell lung cancer: a four arms phase Ib study. Ann Oncol. 2016;27(12):2242-2250. 
26. Reck M, Bondarenko I, Luft A, et al. Ipilimumab in combination with paclitaxel and carboplatin as first-line therapy in extensive-diseasesmall-cell lung cancer: results from a randomized, double-blind, multicenter phase 2 trial. Ann Oncol. 2013;24(1):75-83.

27. Reck M, Luft A, Szczesna A, et al. Phase III Randomized Trial of Ipilimumab Plus Etoposide and Platinum Versus Placebo Plus Etoposide and Platinum in Extensive-Stage Small-Cell Lung Cancer. J Clin Oncol. 2016;34(31):3740-3748.

28. Lynch TJ, Bondarenko I, Luft A, et al. Ipilimumab in combination with paclitaxel and carboplatin as first-line treatment in stage IIIB/IV non-small-cell lung cancer: results from a randomized, double-blind, multicenter phase II study. J Clin Oncol. 2012;30(17):2046-2054.

29. Abdel-Rahman O, Helbling D, Schmidt J, et al. Treatment-related Death in Cancer Patients Treated with Immune Checkpoint Inhibitors: A Systematic Review and Meta-analysis. Clin Oncol. 2017;29(4):218-230.

30. Xu X, Huang Z, Zheng L, Fan Y. The efficacy and safety of anti-PD-1/ PD-L1 antibodies combined with chemotherapy or CTLA4 antibody as a first-line treatment for advanced lung cancer. Int J Cancer. 2018; 142(11):2344-2354.

31. Antonia SJ, López-Martin JA, Bendell J, et al. Nivolumab alone and nivolumab plus ipilimumab in recurrent small-cell lung cancer (CheckMate 032): a multicentre, open-label, phase 1/2 trial. Lancet Oncol. 2016;17(7):883-895.

32. Hellmann MD, Ciuleanu TE, Pluzanski A, et al. Nivolumab plus Ipilimumab in Lung Cancer with a High Tumor Mutational Burden. N Engl J Med. 2018;378(22):2093-2104.

33. Antonia SJ, Villegas A, Daniel D, et al. Durvalumab after Chemoradiotherapy in Stage III Non-Small-Cell Lung Cancer. $N$ Engl J Med. 2017;377(20):1919-1929.

34. Gandhi L, Rodríguez-Abreu D, Gadgeel S, et al. Pembrolizumab plus Chemotherapy in Metastatic Non-Small-Cell Lung Cancer. $N$ Engl J Med. 2018;378(22):2078-2092.

35. Langer CJ, Gadgeel SM, Borghaei H, et al. Carboplatin and pemetrexed with or without pembrolizumab for advanced, non-squamous nonsmall-cell lung cancer: a randomised, phase 2 cohort of the open-label KEYNOTE-021 study. Lancet Oncol. 2016;17(11):1497-1508.

36. Govindan R, Szczesna A, Ahn MJ, et al. Phase III Trial of Ipilimumab Combined With Paclitaxel and Carboplatin in Advanced Squamous NonSmall-Cell Lung Cancer. J Clin Oncol. 2017;35(30):3449-3457.

37. Socinski MA, Jotte RM, Cappuzzo F, et al. Atezolizumab for FirstLine Treatment of Metastatic Nonsquamous NSCLC. $N$ Engl J Med. 2018;378(24):2288-2301.
38. Jotte RM. Primary PFS and safety analysis of a randomized phase III study of atezolizumab + carboplatin + paclitaxel or nab-paclitaxel vs carboplatin + nab-paclitaxel as 1L therapy in advanced squamous NSCLC. J Clin Oncol. 2018;36 (18 Suppl):abstr LBA9000.

39. Paz-Ares LG. Phase 3 study of carboplatin-paclitaxel/nab-paclitaxel with or without pembrolizumab for patients with metastatic squamous non-small cell lung cancer. J Clin Oncol. 2018;36 (suppl; abstr 105).

40. Liu Q, Das M, Liu Y, Huang L. Targeted drug delivery to melanoma. Adv Drug Deliv Rev. 2018;127:208-221.

41. Liu Q, Zhu H, Liu Y, Musetti S, Huang L. BRAF peptide vaccine facilitates therapy of murine BRAF-mutant melanoma. Cancer Immunol Immunother. 2018;67(2):299-310.

42. Liu Q, Zhu H, Tiruthani K, et al. Nanoparticle-Mediated Trapping of Wnt Family Member 5A in Tumor Microenvironments Enhances Immunotherapy for B-Raf Proto-Oncogene Mutant Melanoma. ACS Nano. 2018;12(2):1250-1261.

43. Hou L, Liu Q, Shen L, et al. Nano-delivery of fraxinellone remodels tumor microenvironment and facilitates therapeutic vaccination in desmoplastic melanoma. Theranostics. 2018;8(14):3781-3796.

44. Miao L, Liu Q, Lin CM, et al. Targeting Tumor-Associated Fibroblasts for Therapeutic Delivery in Desmoplastic Tumors. Cancer Res. 2017;77(3):719-731.

45. Ye Y, Wang C, Zhang X, et al. A melanin-mediated cancer immunotherapy patch. Sci Immunol. 2017;2(17):eaan5692.

46. Miao L, Guo S, Lin CM, Liu Q, Huang L. Nanoformulations for combination or cascade anticancer therapy. Adv Drug Deliv Rev. 2017; 115:3-22.

47. Luo W, Wang Z, Tian P, Li W. Safety and tolerability of PD-1/PD-L1 inhibitors in the treatment of non-small cell lung cancer: a meta-analysis of randomized controlled trials. J Cancer Res Clin Oncol. Epub 2018 Jul 17.

48. Khunger M, Rakshit S, Pasupuleti V, et al. Incidence of Pneumonitis With Use of Programmed Death 1 and Programmed Death-Ligand 1 Inhibitors in Non-Small Cell Lung Cancer: A Systematic Review and Meta-Analysis of Trials. Chest. 2017;152(2):271-281.

49. Pillai RN, Behera M, Owonikoko TK, et al. Comparison of the toxicity profile of PD-1 versus PD-L1 inhibitors in non-small cell lung cancer: A systematic analysis of the literature. Cancer. 2018;124(2): $271-277$.
OncoTargets and Therapy

\section{Publish your work in this journal}

OncoTargets and Therapy is an international, peer-reviewed, open access journal focusing on the pathological basis of all cancers, potential targets for therapy and treatment protocols employed to improve the management of cancer patients. The journal also focuses on the impact of management programs and new therapeutic agents and protocols on

\section{Dovepress}

patient perspectives such as quality of life, adherence and satisfaction. The manuscript management system is completely online and includes a very quick and fair peer-review system, which is all easy to use. Visit http://www.dovepress.com/testimonials.php to read real quotes from published authors. 